\title{
Åbenrå Museums Løjt-stue
}

\section{Af Sigvard Skov}

Det sk $\phi$ nne L $\phi j t l a n d$, den bakkede og frugtbare halv $\phi$ mellem Genner bugt og Åbenrå fjord, har i rigt mål fået del i de landskabelige herligheder, skov og strand og bugnende marker mellem levende hegn, som er så karakteristisk for det $\emptyset$ stlige Sønderjylland. Kulturelt svarer hertil en solid bondetradition, hjemstavnsforankret, men med vide udsyn til den store verden $i$ sin dobbelte tilknytning til jordbrug og $s \phi$ fart. Lykkeligt fri for stavnsbåndets tvang var man på mange områder i L $\phi j$ t forud for adskillige egne under den danske krone. Således påbegyndtes udskiftningen allerede $i$ slutningen af 1500 -årene og var stort set afsluttet $i$ midten af det f $\phi$ lgende ${ }^{1}$ ); men landbruget alene var ikke grundlaget for den velstand, der voksede frem i 1700-årene. Det blev skik, at bondes $\phi n n e r$ nogle år for til s $\phi s$, f $\phi \mathrm{r}$ de bofast slog sig ned i deres hjemstavn. I Åbenrå-s $\varnothing$ fartens togter til Kina-

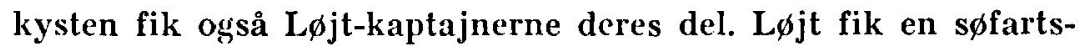
praget kultur, der har paralleler flere steder $\mathrm{i}$ vort land, og hvis nærmeste sidestykke er $R \varnothing m \phi$.

Den velstand, der fandtes i 1700 -årene, og som i nogen grad deltes med bønderne både mod nord og mod syd, gav mulighed for en modernisering af hjem og bolig, ofte f $\phi \mathbf{r}^{\circ}$ de samme idéer var trængt igennem hos kongerigets bønder. I de velbyggede sårde indrettede man sig med kakkelovne og bræddelofter, en nødvendig forudsætning for at den siden så frodige dekorative maling kunne komme til udfoldelse, mens der i de åbne ildsteders tid blot havde været mulighed for det af rogen farvede cgetræ. Til opvarmning af »æ d $\phi$ rns «, dagligstuen, fik man tyske, siden norske bilæggerovne, mens storstuen, »a pisel« kun sjald-

1) Troels Fink: Udskiftningen i S $\varnothing$ nderjylland, 74. (1941) 
nere kunde opvarmes. ${ }^{2}$ ) I de nyindrettede stuer opgav man den fra renaissancen nedarvede ordning med fast bordendebænk. Man fik lose stole og andet indbo, praget af barok og rokoko. I typer og udformning adskilte indboet sig ikke fra borgerskabets boligudstyr. ${ }^{3}$ )

En af de stuer, der indrettedes i 1700-årene, er nu efter tredive års udlændighed nord for Kongeåen vendt tilbage, ikke til Løjt, men til Åbenrå Museum, som nu må være dens rette b jemsted.

Stuen har vinduer med små blyindfattede ruder og derover gardinkapper, i 1700-årene en nymodens skik, som da vandt indpas nærmest under hollandsk påvirkning. Langvæggen overfor vinduerne og den ene tværvæg er panelklædt med indbygget skab, chatol og to alkover. Bade paneler og alkover er typiske træek for tiden og landskabet. De panelklædte stuer var almindeligt udbredt $i$ det frisiske kulturområde, men kendes desuden langs den jyske vestkyst op til Lemvig samt mere spredt andre steder, f. eks. på Læs $\varnothing$, der havde sin egen sфfarerkultur. Alkover kendes tilbage til middelalderen. I Island har de holdt sig fra sagatiden til vore dage. De har varet almindeligt udbredt i Jylland,

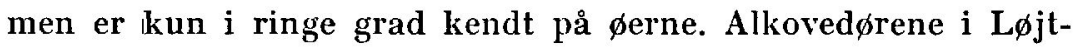
stuen har barokkens fyldinger, een fylding i hver $d \phi r$, tilspidset opadtil og nedefter og omgivet af knækkede og svungne profilbånd. Mellem tværvæggens to alkover er der en $d \phi r$ ud til husets gang, der går på tværs af huset. Til denne side har alkoverne forholdsvis små, ganske enkle skydelåger, der har tilladt forbindelse også til denne side. I langvæggen er indbygget et chatolskab, der har underdel med skuffer, derover en vandret låge, der kan fældes ned som skriveklap, og $\phi$ verst et skab med to låger, der har sprossedelt glas, således at man her har kunnet udstille husets skatte, f. eks. af fajancer. Afslutningen på skabet dannes af en kraftig svunget gavl, hvis volutters rundinger mødes i midten om den her placerede loftbjælke. Under loftet

₹) H. Zangenberg: Gammel Byggeskik i Sønderjyllands Østegne; Turistforeningens Aarbog 1930, 206.

3) Axel Steensberg: Den danske Bondegaard, 130. (1942) 


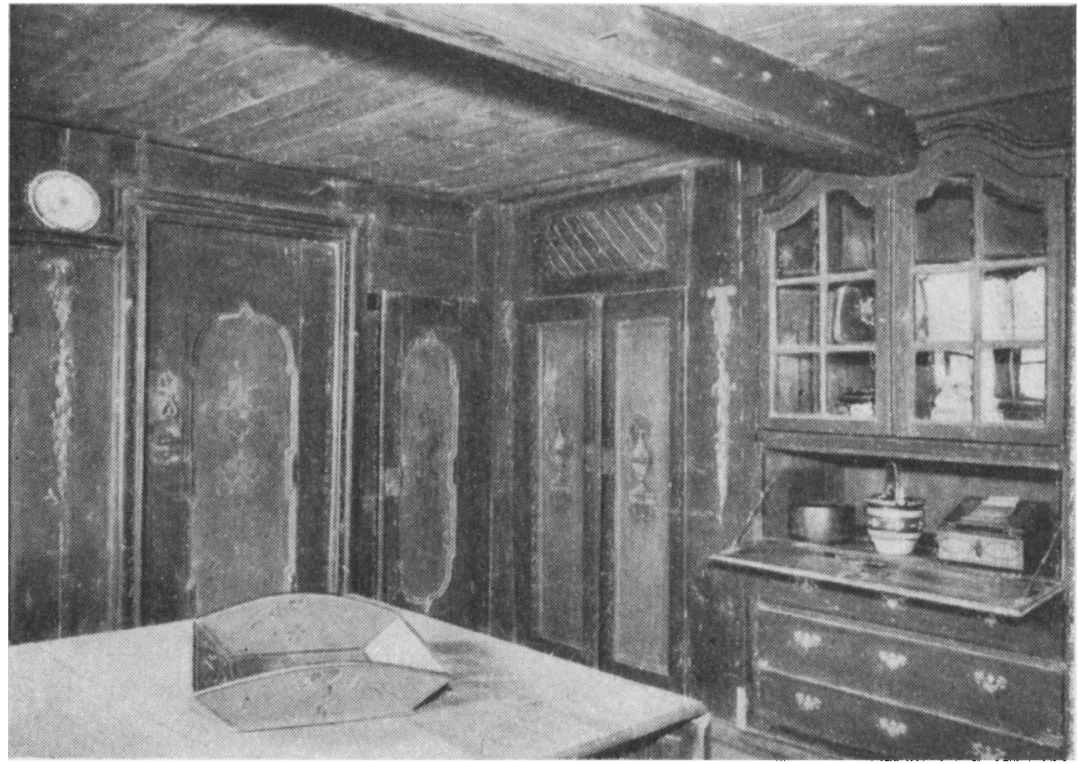

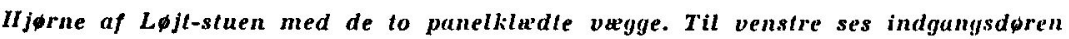
og $i$ midten alkoved det indbyggede skab med glaslåger.

er der en tinrække, hvor tallerkener og fade af tin eller lert $\varnothing \mathbf{j}$ kan anbringes.

Stuen står nu med en velbevaret staffering, der dog nok er nogle årtier yngre end panelværket. Hovedfarven er en mork grøn, og dekorationen udgøres af spinkle blomster- og vasemotiver i brunt og gråt, hvis nyklassiske karakter på en morsom måde danner kontrast til de mere kraftfuldt svungne barokke fyldinger, hvori de er placeret. Blomster og vaser er i den dekorative kunst ikke sjældent forekommende motiver. De findes hyppigt på hollandske fliser, og $i$ en let stiliseret symmetrisk form kunne de uden vanskelighed indpasses i det nyklassiske formskema. I L $\varnothing$ jt kirke har stolestaderne en overdådig malerisk udsmykning med bibelske scenerier og nydelige blomsterbuketter, der viser utvivlsomt slagtskab med blomsterne i den her omtalte panelstue. Stolestaderne er i $\mathbf{1 7 8 5}$ blevet dekoreret af Jes Jessen, malermester i Åbenrå. Der er skellig grund til at tro, at det også 


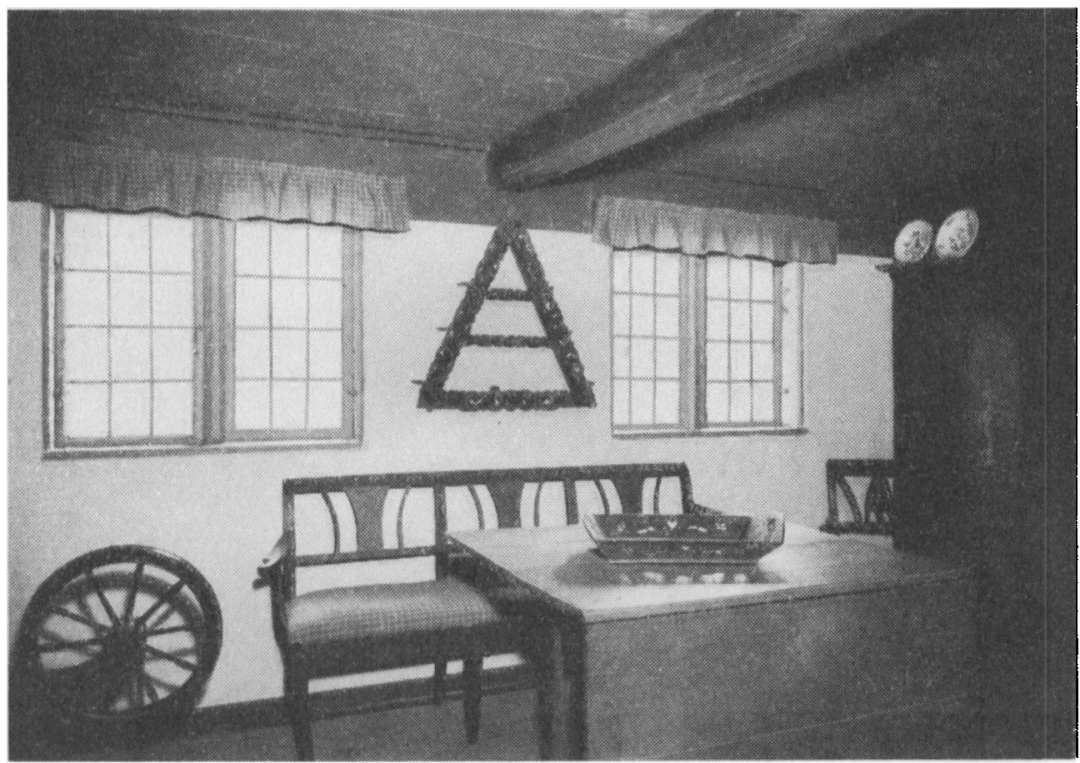

Løjt-stuens vindueswag har smaternede gardiner over de blyiudfattede ruder. Under vinduerne stür den spinkle sofabank og over den hanger tavletten.

er hans pensel, der har prydet alkovedørene med blomster $\mathrm{i}$ vaser. Jes Jessen (1743-1807) var håndværksmester, men havde tillige kunstneriske ambitioner. Hans produktion spænder fra portrætter over altertavler til historiebilleder efter kobberstik. Portrætter findes på Frederiksborg og i Randers Museum, altertavler i Lysabild og Hjordkær kirker og et af historiemalerierne på Koldinghus. Der findes i disse ting både karakteriseringsevne og dekorativ holdning; men når hans navn stadig huskes i dansk kunsts historie, skyldes det ikke blot disse egenskaber, men det at han i årene 1797-1800 havde C. W. Eckersberg som lærling. Lidt af glansen fra dennes storhed er vel altid faldet tilbage på hans første lærer $\mathrm{i}$ håndværket og $\mathrm{i}$ kunsten. Jes Jessen var noget af et provinsgeni, der med frisk mod tog sig de opgaver på, der bød sig inden for faget, men han var først og fremmest håndvarker, og han har foruden mere trivielle ting dekoreret en del udmarkede mobler, hvoraf nogle endnu kendes. Et smukt skab 


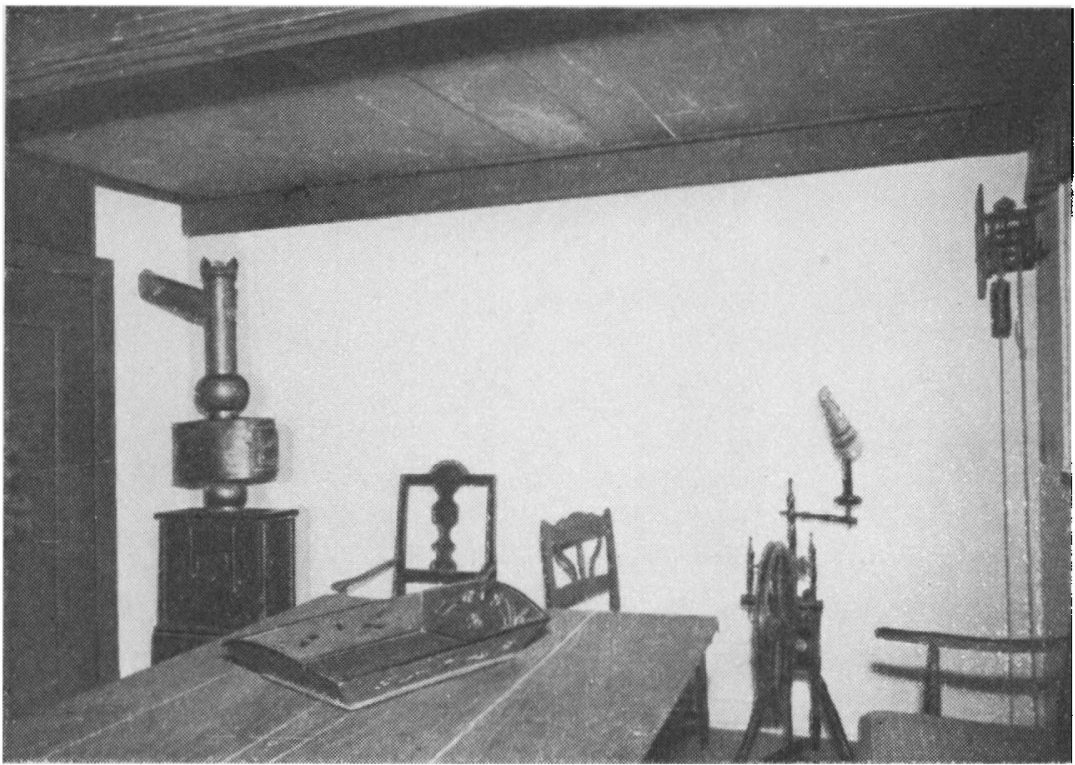

Løjt-stuens kakkelounsveg med jernovn og kobbertromle samt spinderok. Pä vaggen overfor ovnen hanger uret med lodder.

i privat eje prydes med hans karakteristiske blomstervase ${ }^{4}$ ). De fleste dekorationsmalere fra 1700-årene er endnu anonyme; men Jes Jessen og hans vark tegner sig nogenlunde klart for os.

Fra samme tid som den malede dekoration er stuens møbler, der heldigvis også er i behold. Under vinduerne står en spinkel karnapé og foran den et bord med klapper, begge dele udformet under nærmere eller fjernere engelsk påvirkning, hvad sadvanligvis var tilfældet på Løjtland ${ }^{5}$ ). Et par stole, måske har der været flere, af lignende type som karnapéen frembyder det nødvendige antal siddepladser. Over karnapéen mellem vinduerne hanger den trekantede hylde, tavletten, hvor pyntelige småting kunne stilles op. En rok horrer naturligt hjemme i denne som i enhver anden bondestue fra den tid, og noget lignende

4) Axel Steenberg: Danske Bondemøbler nr. 345. (1949); ang. Jes Jessen iøvrigt se: Die Heimat 1914, s. 188-90.

5) Axel Steensberg: Danske Bondem $\emptyset$ bler nr. 26. 
gælder det $\varnothing$ vrige mindre husgeråd, ur med lodder, lysestager af malm samt kobber- og lert $\varnothing \mathbf{j}$, men der kan næppe for disse mere letflyttelige genstande tales om specielle former for L $\phi \mathrm{jt}$.

Sikkert har ejeren og vel ikke mindre konen i gården været glade for deres smukke stue. Den har siden da lykkeligvis undgået omdannelser og moderniseringer. En traditionsbunden konservatisme i forbindelse med, at det s $\phi$ nderjydske landbrug ikke i 1880erne kom ind i så voldsomme $\emptyset$ konomiske omvæltninger, som tilfældet var nord for Kongeåen, bevirkede, at de egne, der fordum var f $\varnothing$ rende $i$ udviklingen, nu kom bagefter, hvad der for bevarelsen af gammelt værdifuldt indbo var en stor fordel. På den tid, Løjt-stuen havde været $\mathbf{i}$ brug $i$ henved et århundrede, begyndte den historiske forskning at interessere sig for de gamle bondegårde, deres byggemåde, indretning og indbo. En af de første, der tog dette studium op, var kulturhistorikeren R. Mejborg (1845-98), der efter en rejse i Nordslesvig i 1892 gav en skildring, der helt passer på vor L $\varnothing j t-s t u e: ~ ઋ n d n u$ findes Gaarde med malede Dekorationer 100 til 120 Aar gamle. Fyldingerne rundt om i Stuen er ofte malede .. og rigt prydede med fine brogede Bouquetter ${ }^{*}$ \&, og han nævner dertil rokokom $\phi$ bler, $\emptyset$ stens kuriositeter og naturalier, minder fra de fjerne have. Efter genforeningen skete meget omfattende moderniseringer hos de sønderjydske bønder, både af driftsformer og af hjem og indbo. Antallet af de panelstuer, der endnu var tilbage, formindskedes hastigt. I erkendelse heraf var det, at Museet på Koldinghus i 1926 købte Jep Fallesens stue. ${ }^{\text {) }}$ (Ganske vist havde Åbenrå i 1887 samtidig med Haderslev og tre år f $\emptyset$ r Koldinghus fået sit museum, men modsat de to nævnte fik det først efter et halvt hundrede år rimelige pladsforhold $i$ egen bygning. Indtil 1920 så Koldinghus det som en af sine særlige opgaver at samle s $\varnothing$ nderjydske minder og havde undertiden lettere ved at få de dansksindede nordslesvigere $i$ tale end visse $i$ landsdelen hjemmehørende, hjemmetyske museumsmænd. Erhvervelse, nedtagning og genopstilling af L $\phi$ jt-stuen var ikke nogen billig

*) R. Mejborg: Nordiske Bøndergaarde I, 220. (1892).

7) O. C. L. Espersen i Vejle Amts Aarbog 1929, 297. 
affære, men en netop modtaget ret stor kontant arv gjorde det alligevel muligt. For at få plads til L $\varnothing$ jt-stuen måtte panoramaet *Skanse II «, dengang et af museets populareste arrangementer, vige. Lфjt-stuen ${ }^{*}$ ) blev placeret umiddelbart op til krigsmindesamlingen og fik senere den restaurerede riddersal på den anden side. Det var ikke nogen heldig placering. Slottets arkitektur umuliggjorde, isier efter riddersalens restaurering, en ordentlig dagsbelysning, og stuen, der skulle være hovedstyklket i museets bondesamlinger, kom til at virke lille, mørk og trykket og uden kontakt med omgivelserne. Da der nylig påbegyndtes en gennemgribende omordning af samlingerne på Koldinghus, viste det sig̨ umuligt at fá Løjt-stuen udstillet inden for slottets mure på en sådan måde, at der ydedes dette værdifulde interiør fuld retfardighed. Med bedrovelse konstateredes, at en passende placering måtte søges andetsteds. Ved formidling af overinspekt $\phi_{1}$ Kai Uldall, Frilandsmuseet, opnåedes uden besvar enighed mellem Koldinghus og Åbenrå Museum, der her fik sin formentlig sidste chance for at komme i besiddelse af en panelstue med indbo frá 1700-årene. Løjt-stuen ${ }^{9}$ ) hører naturligt hjemme på Ábenrå Museum som et uundværligt led i dette museums $\emptyset$ vrige samlinger fra byens og egnens fortid.

8) Koldinghusmuseets årsskrift 1949, 12.

9) Laerer J. Holdt, Rugbjerg, har venligst oplyst, at Løjlstuen stammer fra Øster Elbjerg, der ligger $\emptyset$ st i Løjt Kirkeby. Da stuen blev indrettet, ejedes gården af $\mathrm{Jep}$ Jessen Elbjerg. 